\title{
Is it possible that radiotherapy for local control does not matter in patients with esophageal adenocarcinoma? More studies are needed
}

\author{
Benny Weksler, MD, MBA
}

From the Division of Thoracic Surgery, University of Tennessee Health Science Center, Memphis, Tenn.

Disclosures: B.W. is a proctor for Intuitive Surgery.

Received for publication Jan 11, 2018; accepted for publication Jan 12, 2018; available ahead of print Feb 23, 2018

Address for reprints: Benny Weksler, MD, MBA, Division of Thoracic Surgery, University of Tennessee Health

Science Center, 1325 Eastmoreland Ave, Suite 460, Memphis, TN 38104 (E-mail: bweksler@uthsc.edu).

J Thorac Cardiovasc Surg 2018;155:2708-9

$0022-5223 / \$ 36.00$

Copyright (C) 2018 by The American Association for Thoracic Surgery

https://doi.org/10.1016/j.jtcvs.2018.01.034

Neoadjuvant therapy before resection is the current standard of care for patients with esophageal adenocarcinoma staged higher than stage IIB, and the National Comprehensive Cancer Network recommends preoperative chemoradiation therapy as the preferred treatment. ${ }^{1}$ This recommendation is based on multiple randomized studies that have shown survival advantages for preoperative chemoradiation compared with surgery alone, the most influential of which was the Chemoradiotherapy for Oesophageal Cancer followed by Surgery Study (CROSS) published in 2012. ${ }^{2}$ Randomized studies that compared preoperative chemoradiation with preoperative chemotherapy have not shown a clear survival advantage of chemoradiation relative to chemotherapy, but they have demonstrated a higher rate of complete resection (R0) and a higher rate of downstaging with preoperative chemoradiation. $^{3-5}$

In the current issue of the Journal, Liou and colleagues ${ }^{6}$ report a large study in which they used the National Cancer Database (NCDB) to compare patients who received preoperative chemotherapy with those who received preoperative chemoradiation therapy. Except for tumor size, there were no significant differences in the baseline characteristics of the 2 groups. The vast majority of patients $(91 \%)$ received preoperative chemoradiation. Interestingly, the study revealed strong institutional preferences: 609 facilities $(77 \%)$ treated at least $90 \%$ of their patients with chemoradiation, whereas 11 facilities (4\%) treated more than $90 \%$ of their patients with chemotherapy alone. Patients who underwent preoperative chemoradiation had higher incidences of tumor and nodal downstaging, pathologic complete response, and complete resection. Survival, however, did not differ between the 2 treatments. Liou and colleagues ${ }^{6}$ concluded that radiation therapy before resection may not be uniformly necessary for all patients with esophageal adenocarcinoma.

Studies that use the NCDB are important in gathering population-based information. Even when NCDB studies

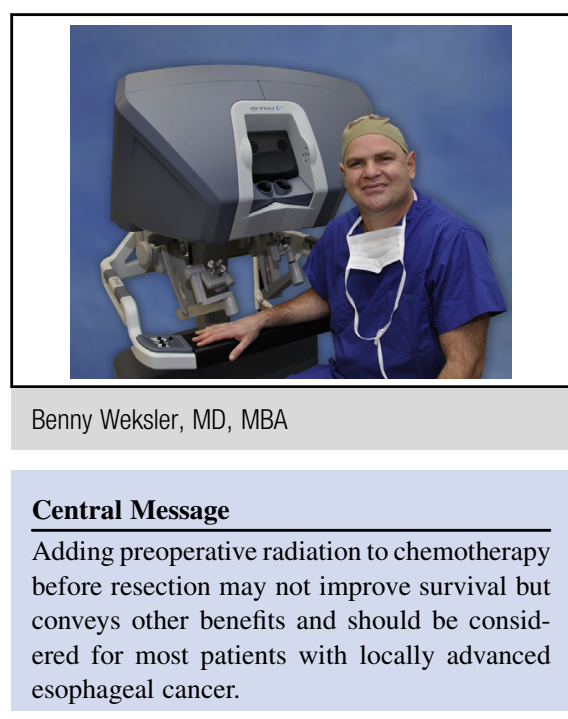

See Article page 2697.

confirm the findings of a randomized trial, however, caution is warranted. Liou and colleagues ${ }^{6}$ did not demonstrate a survival advantage to preoperative chemoradiation, but all parameters for local control (downstaging, pathologic complete response, and complete resection) were improved by adding radiation. Furthermore, the interpretation of several of the randomized studies that compared preoperative chemotherapy with preoperative chemoradiation is far from conclusive. For example, the study of Stahl and colleagues, ${ }^{3}$ which randomized 126 patients to receive either preoperative chemotherapy or preoperative chemotherapy followed by preoperative chemoradiotherapy, closed early because of accrual problems and had a radiation dose (30 Gy) significantly below that used in the CROSS study; however, the investigators still observed a strong trend toward improved survival of patients receiving chemoradiation $(P=.07)$. Burmeister and colleagues ${ }^{4}$ randomized fewer than 40 patients per treatment arm, and patients in the preoperative chemoradiation arm received a relatively low dose of radiation (35 Gy). There were no differences in survival, but patients who received radiation did have a higher rate of complete resection and a higher rate of tumor response. Finally, Klevebro and colleagues ${ }^{5}$ randomized patients to receive chemotherapy or $40 \mathrm{G}$ y of radiation plus chemotherapy preoperatively. Again, there were no 
differences in survival, but patients who received radiation had a higher rate of complete resection and also more pathologic complete responses.

Completeness of resection, downstaging, and pathologic complete response are all important factors affecting survival in patients with esophageal cancer. It is hard to explain how a treatment modality that favorably affects these factors does not affect overall survival. One possibility is that studies have been underpowered to detect differences; another possibility is that the dose of radiation administered was too low. A well-executed randomized trial is urgently needed to determine the value of neoadjuvant radiation in patients with locally advanced esophageal adenocarcinoma. Until then, the clinician will serve his or her patients well by improving local control with preoperative chemoradiation and reserving chemotherapy without radiation for a selected few patients.

\section{References}

1. National Comprehensive Cancer Network. NCCN Clinical Practice Guidelines in Oncology (NCCN Guidelines): Esophageal and Esophagogastric Junction Cancers-NCCN Evidence Blocks, Version 2.2017-August 9, 2017. Available at: https://www.nccn.org/professionals/physician_gls/pdf/esophageal_blocks.pdf. Accessed January 11, 2018

2. van Hagen P, Hulshof MC, van Lanschot JJ, Steyerberg EW, van Berge Henegouwen MI, Wijnhoven BP, et al; Cross Group. Preoperative chemoradiotherapy for esophageal or junctional cancer. N Engl J Med. 2012;366:2074-84.

3. Stahl M, Walz MK, Stuschke M, Lehmann N, Meyer HJ, Riera-Knorrenschild J, et al. Phase III comparison of preoperative chemotherapy compared with chemoradiotherapy in patients with locally advanced adenocarcinoma of the esophagogastric junction. Journal Clin Oncol. 2009;27:851-6.

4. Burmeister BH, Thomas JM, Burmeister EA, Walpole ET, Harvey JA, Thomson DB, et al. Is concurrent radiation therapy required in patients receiving preoperative chemotherapy for adenocarcinoma of the oesophagus? A randomised phase II trial. Eur J Cancer. 2011;47:354-60.

5. Klevebro F, Alexandersson von Döbeln G, Wang N, Johnsen G, Jacobsen AB, Friesland S, et al. A randomized clinical trial of neoadjuvant chemotherapy versus neoadjuvant chemoradiotherapy for cancer of the oesophagus or gastrooesophageal junction. Ann Oncol. 2016;27:660-7.

6. Liou DZ, Backhus LM, Lui NS, Shrager JB, Berry MF. Induction therapy for locally advanced distal esophageal adenocarcinoma: is radiation always necessary? J Thorac Cardiovasc Surg. 2018;155:2697-707. 